Article

\title{
Transition to Low Carbon Electrical Generation for Indonesia
}

\author{
Les Duckers ${ }^{1, *}$, Uswatun Hasanah ${ }^{2}$ \\ 1 School of Energy, Construction and Environment, Coventry University, Priory \\ St, Coventry, CV1 5FB, UK \\ 2 Department of Economics, Universitas Indonesia, 16424, Indonesia \\ * Correspondence: Les Duckers, Email: l.duckers@coventry.ac.uk;
} Tel.: +44-755-742-5784.

\begin{abstract}
This paper explores the options for the transition from fossil fuels to renewables for Indonesia's electricity supply. The stimulus for considering such a transition is the need to reduce carbon emissions whilst meeting the electrical demand. We have modelled a phased replacement strategy in which retiring fossil fuel plants are replaced by renewable plants. The modelling computes carbon emissions, energy output and costs. Such a strategy will take up to 2050 to reduce $\mathrm{CO}_{2}$ emissions to near zero. The modelling was then applied to test more rapid retirement of the fossil fuel plants to obtain near zero emissions by 2040 and then by 2030. All of these strategies were accompanied by reducing costs, largely because of the low and reducing costs of renewables. The modelling was also used to check the sensitivity of the outcome to the assumed costs of fossil fuels and the projected reduction in renewable energy costs. The results show that Indonesia could achieve low carbon electricity generation without extra cost and probably with considerable financial savings. The paper goes on to project an expansion of electrical capacity using renewables, and to propose standalone renewable mini-grids for remote communities as cost effective compared to extending the grid system.
\end{abstract}

\section{G Open Access}

Received: 02 November 2019

Accepted: 15 May 2020

Published: 21 May 2020

Copyright (C) 2020 by the author(s). Licensee Hapres, London, United Kingdom. This is an open access article distributed under the terms and conditions of Creative Commons Attribution 4.0 International License.
KEYWORDS: renewable energy; climate change; carbon emissions; Indonesia

\section{ABBREVIATIONS}

$\mathrm{CO}_{2}$ and $\mathrm{CO}_{2} \mathrm{e}$, carbon dioxide and carbon dioxide equivalent; "Near Zero" is used to describe the condition where $\mathrm{CO}_{2}$ or $\mathrm{CO}_{2} \mathrm{e}$ emissions are extremely small but practically zero; BAU, Business as Usual

\section{INTRODUCTION}

In a previous article [1] we introduced some of the energy issues facing Indonesia, including the contentious problem of coal. Indonesia has an accessible, low sulphur coal resource, which it uses for electrical 
generation and for export. This relatively cheap and economically vital resource is under criticism because of its high $\mathrm{CO}_{2}$ emissions when burned to raise steam to generate electricity. Moving away from coal generated electricity is always assumed to be expensive for Indonesia, and as coal importers around the World also start to restrict their own use of coal the economic impact on Indonesia could be severe. See Cornot-Gandolphe [2]. In this paper we explore possible options for Indonesia to phase in renewable energy technology. We will show that this can be done with reducing greenhouse gas emissions and with reducing costs. The primary objectives of this study were to model the gradual replacement of the existing coal, oil and gas fuelled electrical generation in Indonesia with PV and wind renewable technologies, and to do this completely by 2050; to do this more quickly by 2040; and more urgently by 2030 . The associated objectives were to use the model to calculate carbon emissions and financial outcomes including an analysis of the sensitivity to the range of fossil fuel costs. The other objectives were to explore the financial implications of expanding the grid capacity and providing remote communities with mini grids; both using renewables.

\section{The Current Use of Conventional Energy}

Indonesia has a particularly difficult challenge of providing low carbon energy, especially in the electricity sector, due to its geographical, demographical and socio-economic factors. Reserves of oil and gas, are being rapidly depleted, making Indonesia's energy security weak as she has to import both oil and gas. Because electrical power generation is dominated by coal, gas and oil and takes the substantial portion of the national oil subsidy, a strategy to shift from fossil fuels to renewable energy is necessary. There are currently about 16 oil and gas plants with capacities ranging from 15 to $2255 \mathrm{MW}$, totalling $8446 \mathrm{MW}$ providing $30 \%$ of electricity, and 20 coal plants (60 to $3400 \mathrm{MW}$, totalling 18,630 MW, with as much as a further 17,264 MW planned or under construction) providing $57.2 \%$ of electricity, in Indonesia [3]. With much lower greenhouse gas emissions, renewable energy sources will also help Indonesia to meet its carbon emission reduction target. Hydroelectric and Geothermal plants currently contribute about $12 \%$ of electrical generation. There are many obstacles to Indonesia adopting more renewable energy [4], however in this paper we restrict our considerations to those of carbon emissions and cost. In our modelling, we have sought to reduce the use of fossil fuels by retiring coal, oil and gas generating capacity and replacing them with renewables. This will maintain the current grid capacity. However, the Indonesian policy is to increase supply so that the consumption per person rises to match that of neighbouring countries, see Table 1 . We will address increasing the capacity in this paper. 
Table 1. Electrical consumption per person per year (adapted from [3]).

\begin{tabular}{|l|l|l|l|}
\hline MWh/p/a & Thailand & Malaysia & Indonesia \\
\hline 2018 & 2.70 & 4.90 & 1.02 \\
\hline 2025 projected & & & 2.50 \\
\hline 2050 projected & & & 7.00 \\
\hline
\end{tabular}

\section{The Commitment to Climate Change Reduction (COP21)}

The Paris Agreement (COP21) gained support from around 197 countries in December 2015, with the aim of limiting greenhouse gas emissions in order to restrict the increase in average surface temperature of the World to $1.5 \mathrm{C}$. This is regarded as a vital target as it is a tipping point beyond which we may not be able to stabilize the World climate [5].

\section{Electricity Provision}

Indonesia has strived for more sustainable and environmentally benign energy in recent years. The commitment can be seen in Indonesia's projected energy mix for 2025 compared with 2011. By setting the substantial increase in the renewable energy share to $23 \%$ by 2025 in contrast with $6 \%$ in 2011, the government has demanded a substantial growth in renewable energy deployment.

The current picture of electricity [2]: About $89 \%$ of electricity is provided by fossil fuels and the rest from hydro and geothermal. In 2010 only $68 \%$ of the population had access to electricity, by 2014 this number had risen to $84 \%$, and by 2018 to $95 \%$. This means, though, that people living on many of the small islands still have no access to electricity. Meanwhile, the growth in demand (at 7.1\% per year since 2010) for electricity continues to strain the existing network. Coal is the largest contributor at $57 \%$, and possibly growing, whereas the government's policy to phase out the use of oil has seen a reduction in the consumption of diesel.

\section{Options for Replacing Fossil Fuels}

This paper examines the options for both replacing and augmenting Indonesia's existing power stations. In the previous paper [1] we looked at the economics of operating each power plant to its end of life and then replacing its capacity with a renewable low carbon power plant selected from PV, wind, biomass, wave or hydro. That clearly illustrated that such a strategy makes economic sense and would cut greenhouse gas emissions to near zero. In this paper we explore further options and update the energy costs based on a later Lazard [6] in which renewable costs have generally reduced. The further options examined are (i) consider retiring fossil fuel plants early to bring Indonesia's carbon emissions from electrical generation to near zero by 2040, (ii) to bring them to near zero by 2030, (iii) consider microgrids for isolated islands as opposed to expanding the existing grid network. Although Indonesia has 
considerable renewable resources in six sectors, as illustrated in Table 2, we have restricted this work to the two most economic ones in the US list, namely PV and wind.

Table 2. Indonesia's Renewable Energy Potential, adapted from [3,7].

\begin{tabular}{|l|l|l|} 
Hydro & $75 \mathrm{GW}$ & \\
\hline Geothermal & $29 \mathrm{GW}$ & \\
\hline Biomass & $33 \mathrm{GW}$ & \\
\hline PV & $208 \mathrm{GWp}$ (peak) & $4.8 \mathrm{kWh} / \mathrm{m}^{2} /$ day \\
\hline Wind & $61 \mathrm{GW}$ & \\
\hline Marine & $18 \mathrm{GW}$ & Tidal and Wave \\
\hline
\end{tabular}

\section{Economic Considerations}

The range of cost of electricity generation from renewable and conventional energy sources can be seen in Table 3. There are some advantages of applying the model of the levelized cost of energy (LCOE) because this model provides us the net present value (NPV) of the (total) costs divided by the amount of energy generated in the whole life cycle of the project. Table 3 is taken from the 12th annual review of electricity costs by Lazard [6], which clearly shows the lowest costs are available from wind technology. These costs are based on US technology and conditions, and of course the conditions in Indonesian may be different. In the case of Indonesia, the existing fossil fuel plants are already installed and so we can take the cost of electricity delivered to be based on operating costs. These costs are not clear, and so we have conducted a sensitivity analysis in which we have used the US costs for new fossil fuel plants, and have recalculated using $50 \%, 25 \%$ and $10 \%$ of the US costs for the fossil fuel generating costs.

Table 3. Cost of electricity generated from various energy sources.

\begin{tabular}{|l|c|c|l|c|c|c|}
\hline \multicolumn{1}{|c|}{ Renewable Energy } & \multicolumn{2}{|c|}{$\begin{array}{c}\text { Levelized Cost } \\
\text { US\$/MWh }\end{array}$} & $\begin{array}{c}\text { Conventional } \\
\text { Energy }\end{array}$ & \multicolumn{2}{c|}{$\begin{array}{c}\text { Levelized Cost } \\
\text { US\$/MWh }\end{array}$} & $\begin{array}{c}\text { Operating Cost } \\
\text { US\$/MWh }\end{array}$ \\
\hline & Min & Max & & Min & Max & \\
\hline PV crystalline utility & 40 & 46 & Gas Peaking & 152 & 206 & \\
\hline PV thin film utility & 36 & 44 & Nuclear & 112 & 189 & \\
\hline Geothermal & 71 & 111 & Coal & 60 & 143 & 36.4 \\
\hline Wind & 29 & 56 & Gas CC & 41 & 74 & 51.5 \\
\hline
\end{tabular}

Source: Levelized costs Lazard [6], Operating costs Statkraft [8].

Although PV requires substantial capital costs, resulting in high levelized costs, this source stills looks attractive. Lazard [6], reports that the costs of both PV and wind have fallen by over $68 \%$ during the past nine years, and can be expected to continue to drop as maturing technologies become more efficient, and as mass production reduces manufacturing costs. However, the intermittency of both solar and wind 
resources creates problems with the grid, which could require the continued employment of some fossil fuel power stations to maintain frequency and voltage and to meet the demand in the temporary absence of PV or wind.

\section{Economics of Intermittency}

Alternatives to retaining some fossil fuel power stations on the grid to provide for quiet periods of renewable generation are to use smart grids to match supply to demand and/or to include energy storage. In fact, energy storage is essential where PV or wind are the dominant energy providers. At the time of writing Lazard [9] reports that the cost of battery energy storage (at grid scale of the order of 100 to $200 \$ / M W h$ ), is falling sharply. Scottish Power [10] have a policy of adding PV panels between wind turbines on their small wind farms, which together with battery storage considerably improves the capacity factor of their wind farms. Pumped hydro storage is a means of storing energy over some hours or days. A pumped storage scheme was initiated in 2015 at Upper Cisoka on West Java, with four 260MW Francis pump/turbines. Blakers et al. [11] identified 657 potential sites across Bali alone, with a total storage capacity of $2300 \mathrm{GWh}$, and claim that there is more than enough such sites to support $100 \%$ renewable energy in Indonesia.

\section{METHODOLOGY}

In this modelling the fossil fuel plants included are; six gas fired, 10 oil fired and 20 coal fired generating stations, each with their appropriate installed capacity. The list of fossil fuel capacities is included in the Appendix.

In this modeling we have used the US cost data from Lazard [6,12]. The capacity factor, greenhouse gas emissions, as $\mathrm{CO}_{2} \mathrm{e}$ and cost of the energy sources are given in Table 4 . Note that the low capacity factors for wind and PV reflect the reliance of these sources on the intermittent availability of wind and sun, whereas the other energy sources are limited only by technical aspects of their operations such as repair and maintenance periods, and so have capacity factors close to 1 (or 100\%).

Table 4. Energy source (fossil and renewable), capacity factor, greenhouse gas emissions, and cost.

\begin{tabular}{|l|c|c|c|c|}
\hline \multirow{2}{*}{ Energy Source } & capacity factor & $\mathbf{C O}_{2} \mathbf{e} \mathbf{t} / \mathbf{M W h}$ & $\mathbf{\$} / \mathbf{M W h}$ & Operating costs used in sensitivity analysis \\
\cline { 3 - 5 } & & 0.4 & 85 & $\$ / \mathrm{MWh}$ \\
\hline gas & 0.9 & 1.0 & 105 & $8.5 / 21 / 42$ \\
\hline coal & 0.8 & 0.85 & 120 & $10.5 / 26 / 52$ \\
\hline oil & 0.25 & 0.02 & 40 & $12 / 30 / 60$ \\
\hline PV & 0.3 & 0.02 & 42.5 & \\
\hline wind & 0.9 & 0.02 & 94 & \\
\hline Biomass & 0.7 & 0.02 & 83 & \\
\hline Hydro & & & & \\
\hline
\end{tabular}

Source: authors $[6,12]$. 
In the model we calculate the annual energy produced from each power station, the total annual cost of energy delivered and the annual $\mathrm{CO}_{2}$ emissions. We do this for the year 2020, and repeat for subsequent years up to 2050. This, of course, assumes that all of the power stations continue to operate over that period, or are replaced by the same type of generator. This is Business as Usual (BAU).

\section{Modelling a Strategy for Indonesia}

We suggest a complete conversion strategy from fossil fuels to wind and $\mathrm{PV}$ renewables over a period of years to reach zero $\mathrm{CO}_{2}$ emissions. It is impossible to generate electricity with zero emissions since both wind and PV technologies still require some contribution from fossil fuels in their life cycle and so have a modest emission of $0.02 \mathrm{t} \mathrm{CO}_{2} / \mathrm{MWh}$. We will therefore use the term "near zero" to describe the target for minimising $\mathrm{CO}_{2}$ emissions from electrical generation in Indonesia.

The modelling of strategies is done in several stages:

Stage 1. BAU.

Stage 2. By retiring some of the gas, oil and coal plants from the list in the appendix and replacing them with $\mathrm{PV}$ and wind stations, with appropriate consideration of load factors, so that total electrical energy delivered is maintained. The model then computes the total annual cost and total annual $\mathrm{CO}_{2}$ emissions. The "near zero" condition is met by 2050.

Stage 3. Repeat stage 2, but with fossil fuels plants retired earlier the "near zero" condition is met by 2040.

Stage 4. Repeat stage 2, but with even more rapid retirement of fossil fuel plants "near zero" is achieved by 2030.

Stage 5. A doubling of the electricity provision is achieved by introducing more PV and wind.

Stage 6. A sensitivity analysis is conducted to test if applying lower operating costs of fossil fuel plants significantly alters the outcome.

\section{RESULTS}

Stage 1. BAU: Since nothing changes through the years from 2020 to 2050

The annual electricity output is about 200 TWh. Annual carbon dioxide emissions are $160 \mathrm{MtCO}_{2}$ and the annual electricity cost is $\$ 20 \mathrm{Bn}$. The results for the annual electrical output for Stages 2, 3 and 4 are shown in Figures 1, 2 and 3.

Stage 2. Near Zero by 2050

The costings for energy have been updated using the 2018 version of Lazard. This leads to a slight reduction in the total cost and the cost per MWh, simply due to the continued decrease in cost of wind and PV energy. 
By introducing PV and wind to replace obsolete or retired fossil fuel plants (at a rate of about one plant per year) the $\mathrm{CO}_{2}$ emissions can be reduced to "near zero" by 2050, whilst the total cost of energy falls by about $30 \%$ over the same period. This scenario, though, fails to meet the Indonesian target of 23\% from renewable sources by 2025 .

Stage 3. Near Zero by 2040

The fossil fuel plant are expensive and emit significant amounts of carbon dioxide. By bringing forward their retirement dates, in an orderly sequence of around two plants per year, the overall system retains stability and there is sufficient installation capacity to commission PV and wind at an acceptable rate. Note that this means that Indonesia could reach "near zero "emissions by 2040: some ten years early than the replace on retirement scenario. This meets the Indonesian policy of $23 \%$ from renewable sources by 2025.

Stage 4 . Near zero by 2030

Increasing the rate of retirement to about four plants per year, brings the $\mathrm{CO}_{2}$ emissions down rapidly to achieve "near zero" by 2030 .

Results for Carbon emissions are shown in Figure 4. Cumulative emissions over the period 2020 to 2050 are "BAU" $4653 \mathrm{Mt}$, "near zero by 2050” 2843 Mt, "near zero by 2040” 2015 Mt, "near zero by 2030” $1236 \mathrm{Mt}$. Indonesia could avoid emitting $3417 \mathrm{Mt} \mathrm{CO}_{2}$ over the period 2020 to 2050 by adopting the near zero by 2030 strategy.

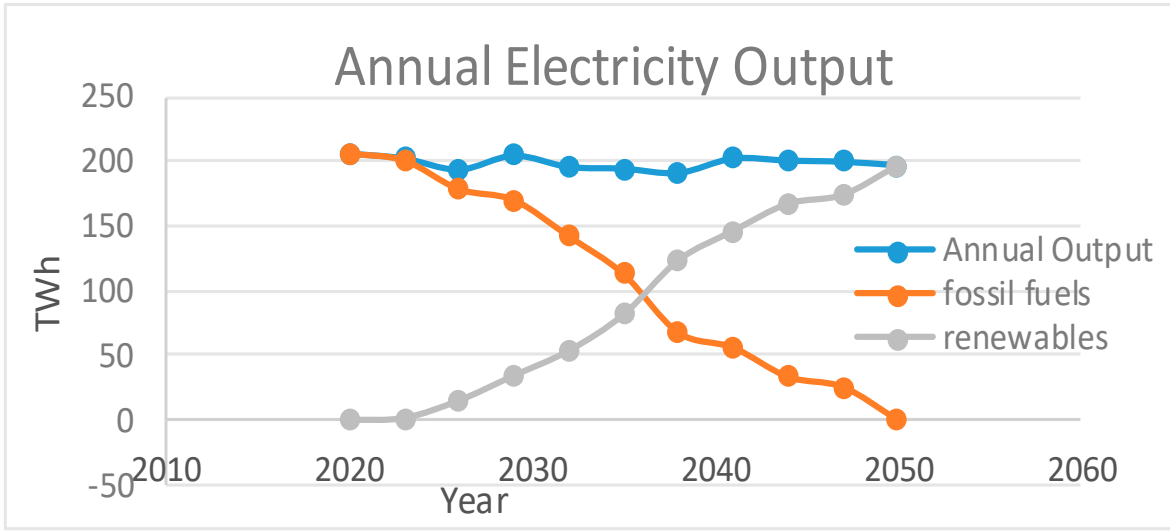

Figure 1. Annual Electrical Output for Stage 2; Near zero by 2050. 


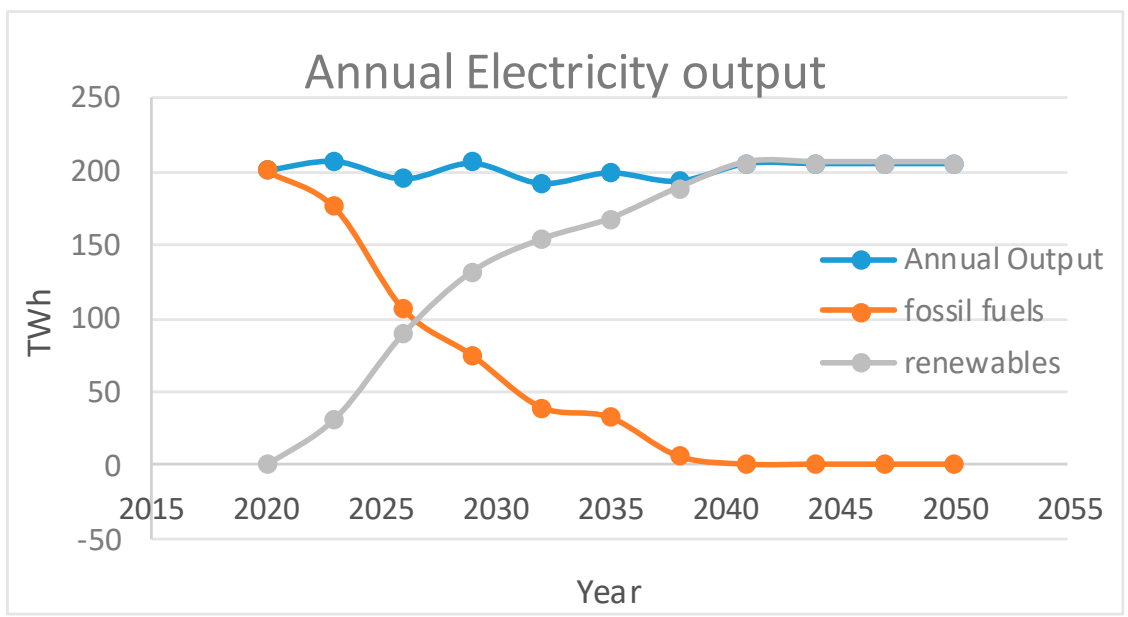

Figure 2. Annual Electrical Output for Stage 3; Near zero by 2040.

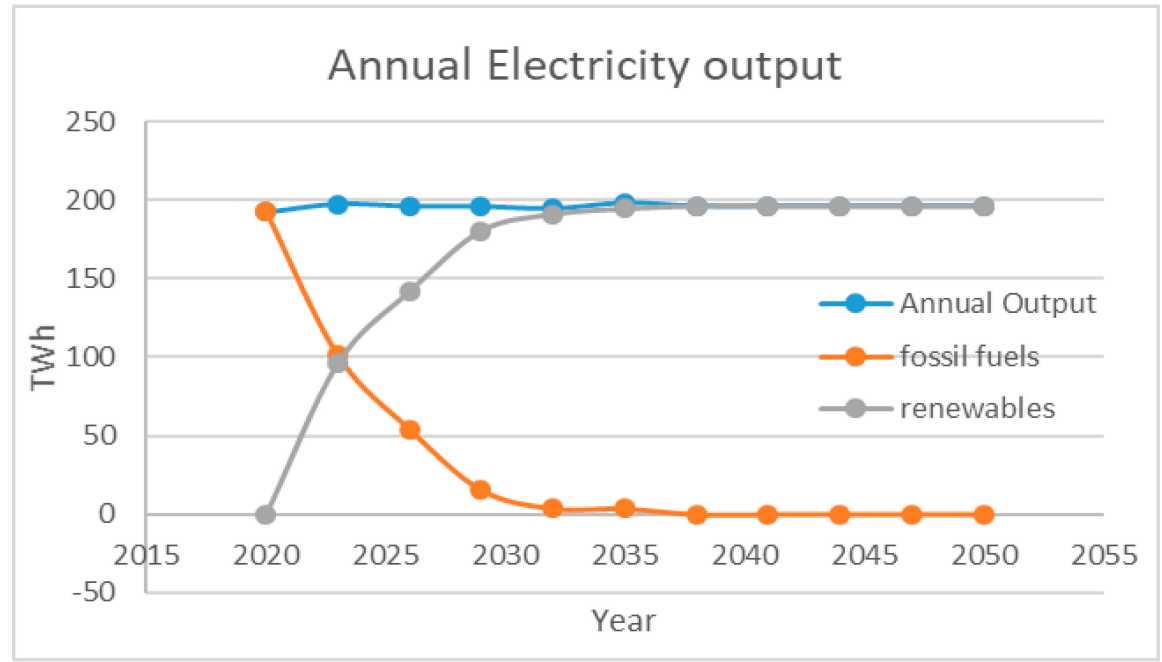

Figure 3. Annual Electrical Output for Stage 4; Near zero by 2030.

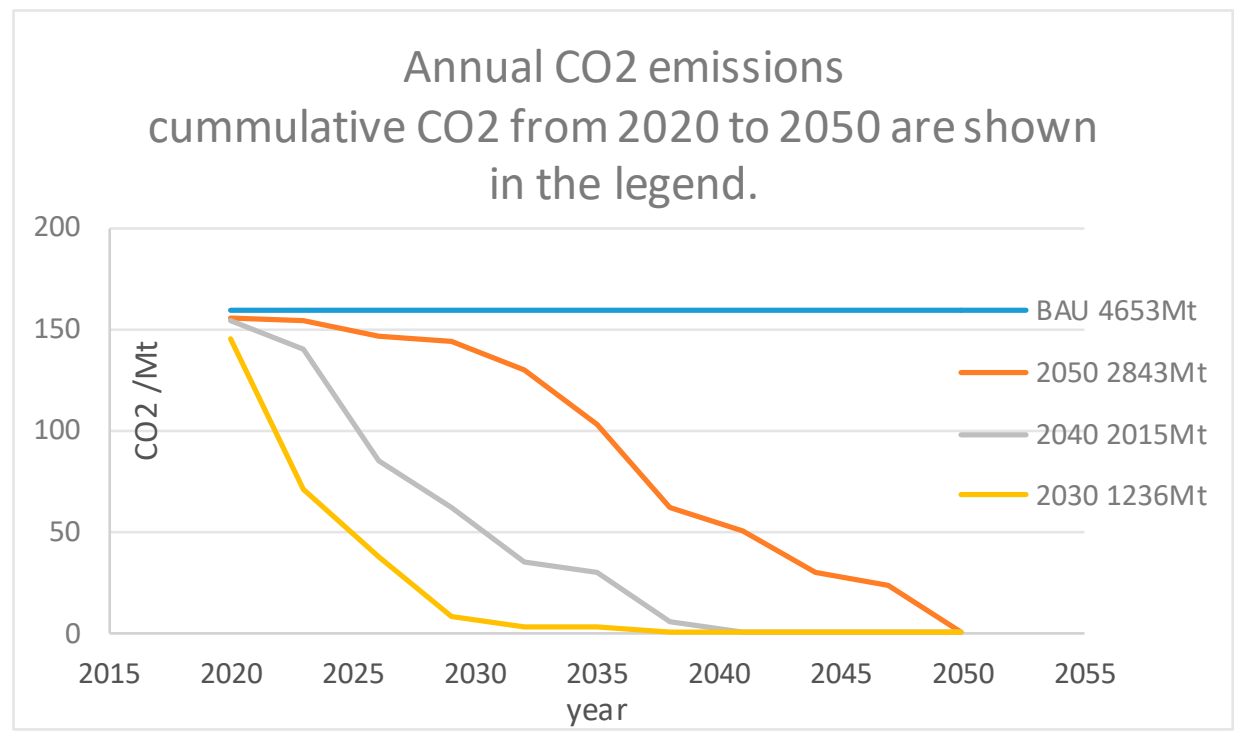

Figure 4. Annual carbon dioxide emissions under the various stage scenarios. 
The total cumulative carbon dioxide emissions for 2020 to 2050 are shown in the legend.

Stage 5. Increasing installed electrical capacity

By more than simply replacing fossil fuel plants with renewable capacity, this scenario shows, in Figure 5, a doubling of annual energy delivered, and the near zero condition is reached by 2030. The total annual cost, which is shown in figure 6, initially drops from the fossil fuel value, but then slowly increases as the installed capacity grows, but the unit cost remains low. It is similarly possible to continue the $7 \%$ annual growth rate over the period 2020 to 2050, which means increasing the delivered electrical energy from renewables by seven times to $1400 \mathrm{TWh} / \mathrm{a}$. There is sufficient renewable resource in Indonesia to supply this, and it is predicted, based on Lazard [6], that the unit cost will fall during this period.

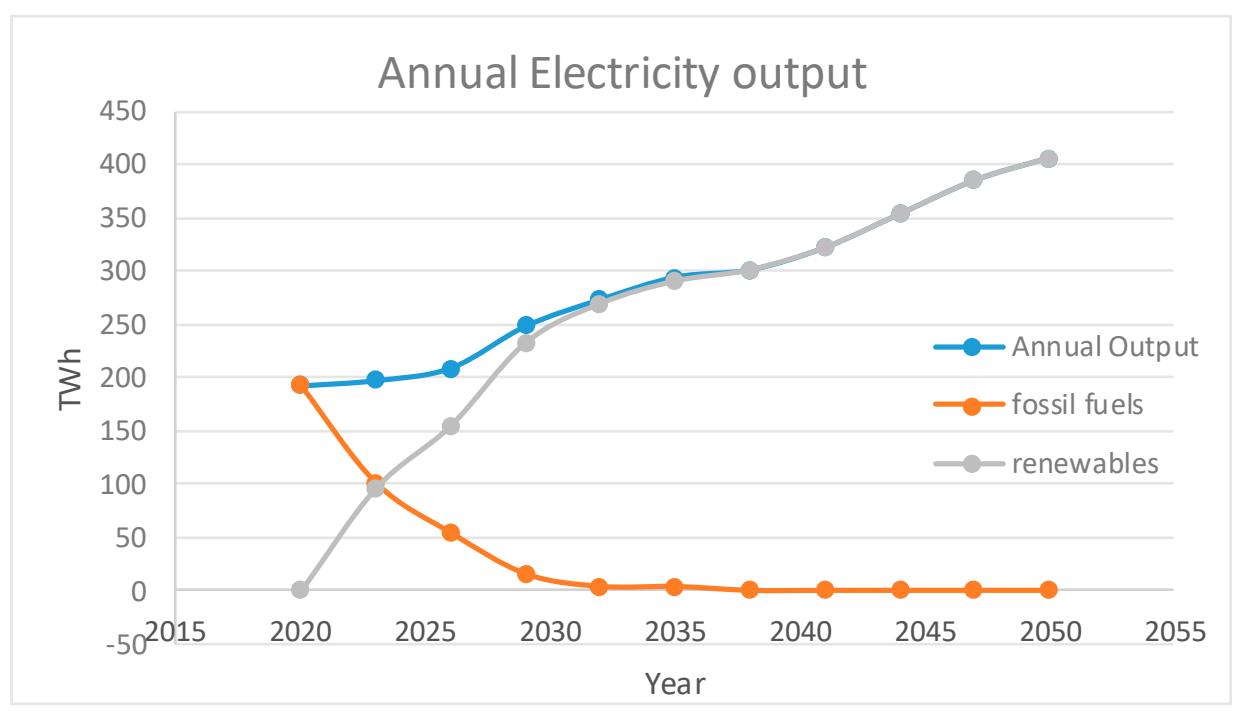

Figure 5. Annual Electricity output with double capacity.

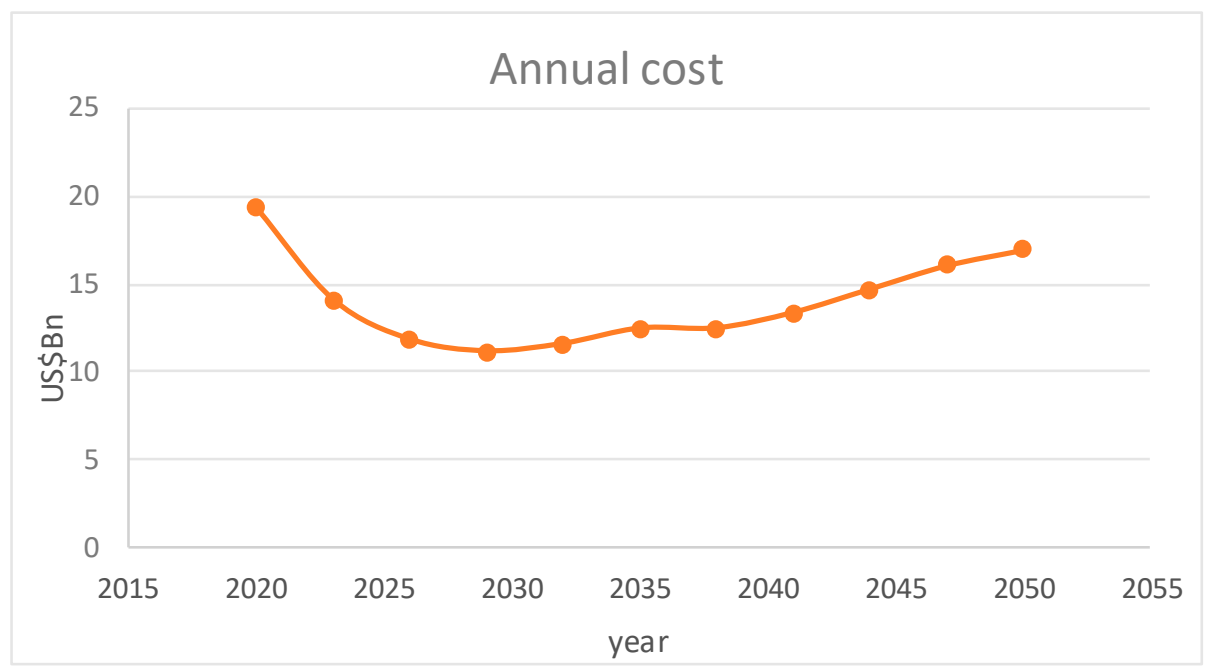

Figure 6. Annual cost of electricity with double capacity. 
Stage 6. Financial considerations. Sensitivity analysis of fossil fuel cost

A major consideration for the implementation of a carbon reduction policy as suggested by our modelling will be financial. On the basis of the costs from Lazard [6] we would advocate adopting a rapid adoption of renewable energy this minimises both total cost and total $\mathrm{CO}_{2}$ emissions. The question of fossil fuel costs in Indonesia, though, is uncertain and it may be that we should not accept the US costs.

Indonesia has had a very laudable history of energy subsidies designed to help the poor and less privileged [13]. A meeting of G20 countries, and Indonesia's self-reflection [14] concluded that such subsidies are largely more help to richer sections of society who have access to energy consuming dwellings and vehicles, and actually encourage consumption of energy since the price is held artificially low. In the modelling reported above we have used US costs for all forms of energy, which we believe to reflect the relative costs of the technologies. However, in order to test the importance of real costs in the Indonesian electricity grid we have conducted a sensitivity analysis to test our conclusions. We have therefore run our model with the cost of fossil fuels taken to be $50 \%, 25 \%$ and $10 \%$ of the US costs. This will accommodate the possibility that some of the source fossil fuels are indigenous (Indonesia has coal, but largely imports oil, LNG and gas) and so are cheaper for the electrical generators. This also accommodates the subsidy arrangements, which perhaps have made electricity cheaper, but masking the true cost, and allows for the fossil fuel costs to be operational costs only since the plants already exist.

Figure 7 shows the cost of electrical energy relative to a reference case (100\% US coal costs in near zero year 2030) when the cost of coal is taken as $50 \%, 25 \%$ and $10 \%$ of US costs.

The results show that, using the Lazard [6] values for fossil fuels, overall costs rise (see the red line from the reference case) as the date to reach near zero $\mathrm{CO}_{2}$ emissions increases from 2030 to 2050. On this basis the earliest date is the preferred financial option, and of course this minimises the cumulative $\mathrm{CO}_{2}$ emissions. This remains the case even if we accept that Indonesian fossil fuel costs are $50 \%$ of US ones. The situation is slightly reversed if fossil fuels are $25 \%$ of US ones, and if they are $10 \%$ of US ones overall costs are reduced if the date to reach near zero is delayed until 2050. 


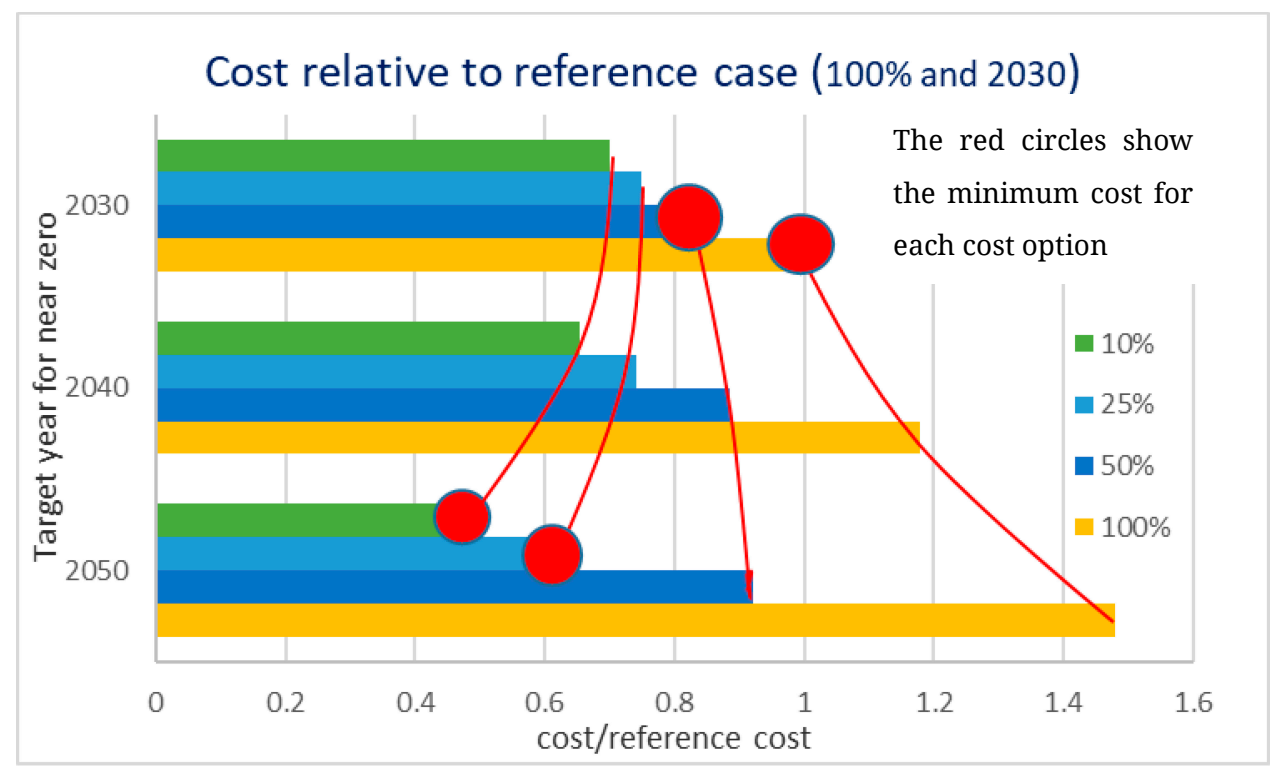

Figure 7. Sensitivity of total cost to the cost of coal generation. For each "near zero" year, and for each proportion of US coal costs, the costs of electricity are shown relative to the reference case (Near Zero at 2030, and $100 \%$ US coal costs).

\section{Remote Communities}

Many of Indonesia's population live away from the National Grid, and so any strategy should include consideration of providing electricity to remote communities, many of which occupy some of the 17,000 islands. The option of extending the national grid using submarine cables to service remote islands would have been considered in the past, but a cheaper option may be to install micro and mini grids in the vicinity of the communities. Submarine cables can cost of the order of $0.6 \$ \mathrm{M} / \mathrm{km}$. [15], and 59 Scottish Islands are connected to the UK mainland via submarine cables. However, given the recent costs reported by Lazard [6], wind and utility PV represent good economical choices to provide electricity to remote and isolated communities, especially where the length of cable required is large. Demand on small grids will be relatively more variable than would be the case on large, national grids where the smoothing effect of many consumers and the ability of burn fossil fuel on demand means that supply and demand can be readily matched. Add to this the variability of the energy sources of wind and PV and the problem of matching supply and demand is more complex. We have modelled this by considering a typical community to have 100 houses. Figure 8 shows how the demand (from Uwah [16]) varies over $24 \mathrm{~h}$. 


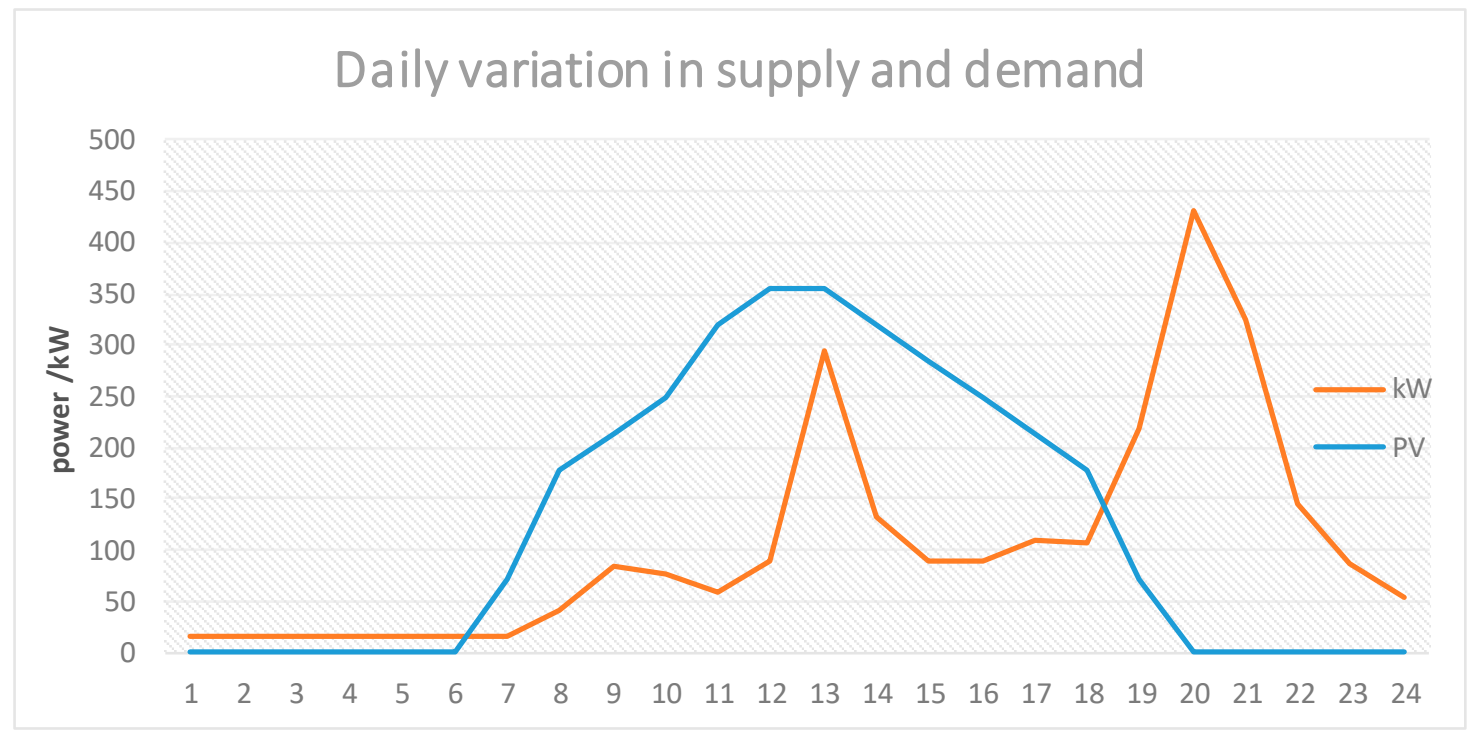

Figure 8. Typical supply/demand curve for a community of 100 houses. The supply curve is from a PV array (labelled PV). The demand curve (labelled kW) is taken from Uwah [16].

An installation of a PV array of $350 \mathrm{~kW}$ will deliver electricity as illustrated in Figure 8. The two curves are not identical and there is a surplus of supply from about $7 \mathrm{am}$ to $7 \mathrm{pm}$. This electricity can be stored (in batteries) for use in the evening. The analysis by Lazard [9] describes the choice of energy storage, and also points to the reducing cost of energy storage. We have costed the grid for 100 houses, with utility PV and $2000 \mathrm{kWh}$ of storage. The average cost of delivered electricity is estimated at 44-55 \$/MWh.

Apart from anticipating that renewable costs will continue to fall for some years, we can also consider that energy efficiency and conservation will effectively reduce costs. Light emitting diodes (LED) for example are much more efficient than both conventional light bulbs and compact fluorescent bulbs, (84, 12 and $60 \mathrm{~lm} / \mathrm{W}$ respectively). The slightly higher capital cost of LED is quickly repaid in much reduced running costs. Conservation of energy is also important, and simply switching off unwanted appliances can yield significant savings. McKinsey [17] have explored a wide range of carbon emission mitigation measures and provide a ranked chart of cost per $\mathrm{t}$ of $\mathrm{CO}_{2}$ avoided against amount of $\mathrm{CO}_{2}$ avoided. The significant feature of their results is that about half of the measures actually save money as well as avoiding $\mathrm{CO}_{2}$. Low energy lighting is in this category.

\section{Case Study: Fair Isle, UK}

Fair Isle is a remote Scottish island, located $40 \mathrm{~km}$ north of the Scottish mainland. The population of 60 people historically relied on two diesel generator sets, (of $20 \mathrm{~kW}$ and $50 \mathrm{~kW}$ ) which meant that their electricity was expensive (in the 1980s $40 \$ / \mathrm{MWh}$ ) due largely to the cost of transporting diesel fuel. 
This is the situation in many parts of Indonesia, Papua, for example has energy costs ten times that of Java or Bali [3]. Demand for electricity was understandably low, and diesel was conserved by restricting the use of the generators to a few hours each morning and each evening. In 1982 the island installed a single $50 \mathrm{~kW}$ wind turbine, which proved to be so popular because it delivered electricity for about $10 \%$ of the cost from diesel. Island residents selected when to use the diesel generated and when to use the wind generated electricity based on viewing the rotation of the wind turbine. Electricity on Fair Isle was then cheaper than anywhere else in the UK, and demand for electricity grew so that a second wind turbine was installed. Sinclair et al. [18] describe the first turbine operational year. As the original wind turbines reached their end of life, they have been replaced by three $60 \mathrm{~kW}$ turbines, complemented by a $50 \mathrm{~kW}$ solar PV array and $500 \mathrm{kWh}$ of lead acid batteries to provide about $50 \mathrm{~h}$ of storage. This recent electricity scheme provides $24 \mathrm{~h}$ assured supply to Fair Isle.

\section{DISCUSSION}

The modelling shows that the low cost of wind and PV technologies, which are now competitive with fossil fuels and nuclear energy, could be deployed in a phased manner to replace Indonesian fossil fuel plants as they reach their end of life. This is in agreement with the general strategy proposed by Statkraft [8]. In following this strategy, Indonesia would reduce its carbon emissions to near zero by 2050. The situation could be accelerated by retiring fossil fuel plants before they reach end of life; at a rate of about two plants per year near zero would be achieved by 2040, and at four plants a year by 2030. Financially, Indonesia would save money with any of the strategies modelled here. The key assumption on cost of coal generation in Indonesia being more expensive that wind or PV has been tested by a sensitivity analysis in which coal was costed at $100 \%$ ( the baseline), $50 \%, 25 \%$ and $10 \%$. If near zero is achieved by 2030 there is little sensitivity to cost, whereas if near zero is delayed until 2050 the cost of coal becomes dominant.

\section{CONCLUSIONS}

The primary and associated objectives of this study have been met, showing that a programme of phased replacement of fossil fuel generating plants with PV and wind arrays could be financially attractive for Indonesia, and reduce the associated carbon emissions to near zero. By adopting the earliest closure of fossil fuels plants Indonesia could avoid emitting $3417 \mathrm{Mt}$ of carbon over a 30 period. This study is limited by a lack of knowledge of the exact present cost of generation in Indonesia but a sensitivity analysis confirms the general conclusions.

The other objectives, on increasing capacity by adding more PV and wind arrays, and introducing micro-grids to remote communities, suggest that renewable energy, accompanied by energy management and energy 
storage measures offers an economic route to increased electricity provision.

\section{AUTHOR CONTRIBUTIONS}

UH collected the data on Indonesia, and provided the interpretation in the Indonesian context. LD performed the modelling. Both authors conducted the analysis and drafted the paper.

\section{CONFLICTS OF INTEREST}

The authors declare that there is no conflict of interest.

\section{APPENDIX}

Table A1. List of fossil fuel plant capacities (the coal plants are in pairs).

\begin{tabular}{|c|c|}
\hline Plant type & MW \\
\hline gas plant 1 & 764 \\
\hline gas plant 2 & 2255 \\
\hline gas plant 3 & 920 \\
\hline gas plant 4 & 1208 \\
\hline gas plant 5 & 1334 \\
\hline gas plant 6 & 1430 \\
\hline coal plant 1,11 & 1060 \\
\hline coal plant 2,12 & 3600 \\
\hline coal plant 3,13 & 2925 \\
\hline coal plant 4,14 & 2640 \\
\hline coal plant 5,15 & 1260 \\
\hline coal plant 6,16 & 1650 \\
\hline coal plant 7,17 & 830 \\
\hline coal plant 8,18 & 830 \\
\hline coal plant 9,19 & 1995 \\
\hline coal plant 10,20 & 690 \\
\hline oil plant 1 & 130 \\
\hline oil plant 2 & 70 \\
\hline oil plant 3 & 150 \\
\hline oil plant 4 & 92 \\
\hline oil plant 5 & 100 \\
\hline oil plant 6 & 150 \\
\hline oil plant 7 & 15 \\
\hline oil plant 8 & 400 \\
\hline oil plant 9 & 120 \\
\hline oil plant 10 & 200 \\
\hline
\end{tabular}




\section{REFERENCES}

1. Hasanah U, Duckers L. An outline economic strategy for Indonesia to sustainably meet its electricity and carbon emissions. Central Eur Rev Econ Manag. 2018;2(4):39-54.

2. Cornot-Gandolphe S. Indonesia's Electricity Demand and the Coal Sector: Export or meet domestic demand? Oxford (UK): The Oxford Institute for Energy Studies; 2017.

3. PwC. Power in Indonesia: Investment and Taxation Guide. 6th ed. Jakarta (Indonesia): PwC Indonesia; 2018.

4. Dutu R. Challenges and Policies in Indonesia's Energy Sector. Energy Policy. 2016;98:513-9.

5. Arshad A. Indonesia's Parliament ratifies Paris Agreement on Climate Change. The Straits Times. 2016 Oct 19. Available from: http://www.straitstimes.com/asia/se-asia/indonesias-parliament-ratifies-pari s-agreement-on-climate-change. Accessed 2017 Aug 15.

6. Lazard. Levelized cost of energy analysis-version 12. Hamilton (Bermuda): Lazard; 2018. Available from: https://www.lazard.com/media/450784/ lazards-levelized-cost-of-energy-version-120-vfinal.pdf. Accessed 2019 Aug 23.

7. Statistik EBTKE. Direktorat Jendral Energi Baru dan Terbarukan dan Konservasi Energi ("Ditjen EBTKE") (2016 EBTKE Statistics issued by Directorate General of New and Renewable Energy and Energy Conservation (“DGNREEC”)). Jakarta (Indonesia): Statistik EBTKE; 2016. Indonesian.

8. Statkraft. Global energy trends: Statkraft's Low Emissions Scenario. Available from: https://www.statkraft.com/. Accessed 2019 Oct 12.

9. Lazard. Lazard's Levelized cost of storage analysis-version 4.0. Hamilton (Bermuda): Lazard; $2018 . \quad$ Available from: https://www.lazard.com/media/450774/lazards-levelized-cost-of-storage-versi on-40-vfinal.pdf. Accessed 2019 Aug 23.

10. Stoker L. 2019. Available from: https://www.current-news.co.uk/news/ scottishpower-lifts-lid-on-major-solar-wind-battery-storage-hybrid-strategy-f or-uk-and-ireland. Accessed 2020 Jan 16.

11. Blakers A, Lu B, Stocks M. Indonesia has far more than enough pumped hydro storage sites to support $100 \%$ renewable energy electricity grid. The Conversation. 2018 May 3.

12. Lazard. Levelized cost of energy analysis-version 11. Hamilton (Bermuda): Lazard; 2017. Available from: https://www.lazard.com/media/450337/ lazard-levelized-cost-of-energy-version-110.pdf. Accessed 2018 Dec 5.

13. Burke PJ, Kurniawati S. Electricity subsidy reform in Indonesia: Demand-side effects on electricity use. Energy Policy. 2018;116:410-21.

14. G20. Indonesia's Effort to Phase out and Rationalise its Fossil Fuel Subsidies. Jakarta (Indonesia): Ministry of Mining and Mineral Resources, and Ministry of Finance, Republic of Indonesia; 2019.

15. SSE. Submarine Electricity Cables Cost Benefit Analysis Methodology Statement. Scotland (UK): Scottish and Southern Energy Stakeholder Consultation; 2015. 
16. Uwah UT. Feasibility study for the development of renewable based microgrids in Costa Rica [MSc Thesis]. Coventry (UK): Coventry University; 2014.

17. Pathways to a low-carbon economy. New York (NY, US): McKinsey and Company; 2009. Available from: https://www.mckinsey.com/ /media/ mckinsey/dotcom/client service/sustainability/cost\%20curve\%20pdfs/pathw ays lowcarbon economy version2.ashx. Accessed 2018 Sep 2.

18. Sinclair BA, Stevenson WG, Somerville WM. Wind Power Generation on Fair Isle. In: Energy for Rural and Island Communities. Proceedings of the Third International Conference; 1983 September; Inverness, Scotland. Bergama (Turkey): Pergamon; 1984. p. 155-62.

How to cite this article:

Duckers L, Hasanah U. Transition to Low Carbon Electrical Generation for Indonesia. J Sustain Res. 2020;2(3):e200024. https://doi.org/10.20900/jsr20200024 